\title{
En direct de www.la-maison-du-cancer.com
}

\section{amaisonDucalncer \\ s'informer, s'entraider, témoigner}

Oncomagazine a choisi d'ouvrir régulièrement ses colonnes à La-maison-du-cancer.com, site sociétal dédié à la manière de vivre le cancer au quotidien. Nous inaugurons cette rubrique par un témoignage d'une patiente sur les bouleversements que le cancer provoque dans la vie professionnelle.

www.la-maison-du-cancer.com est un site d'information sur le cancer à destination des malades, de leurs proches, du personnel soignant et de toute personne sensibilisée à ce fléau. Il cherche notamment à répondre aux difficultés professionnelles, administratives et financières, mais aussi relationnelles, esthétiques, pratiques qui se posent aux malades. Son objectif est ainsi de soulever le problème de la « double peine » qui les frappe. Le site entend également créer une communauté dynamique et active pour réussir à changer le regard de la société sur les malades du cancer.

Carole : « Les entreprises ne sont pas prêtes à accueillir des gens comme moi »

Avoir un cancer bouleverse aussi la vie professionnelle. De la difficulté à garder le contact avec l'entreprise pendant les traitements aux relations transformées avec les collègues et la hiérarchie en passant par la reprise du travail malgré la fatigue et les effets secondaires... voici le témoignage de Carole, 31 ans.

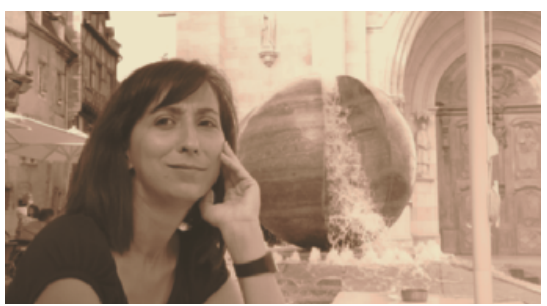

" J'étais assistante RH dans une grande entreprise depuis 2004. J'avais choisi une société de taille importante pour pouvoir évoluer, avoir petit à petit plus de responsabilités... Un espoir stoppé net par une grosse tuile : début 2007, on m'a dia- gnostiqué un carcinome papillaire de la thyroïde. J'avais 29 ans. Après deux opérations, on a trouvé des métastases aux poumons. Je suis actuellement des cures d'iode auxquelles je réagis bien.

Mon chef direct m'a appelée la veille de ma première opération de thyroïdectomie uniquement pour savoir où étaient mes dossiers. Je comprends que mon absence crée des problèmes d'organisation, mais il a osé me dire que l'intérimaire qui me remplace s'interrogeait sur son avenir et qu'il fallait que je me mette à sa place. Mais qui se met à la mienne ? La question que je me pose sur mon avenir, c'est de savoir si je vais vivre ou mourir.

Quand j'étais en arrêt, c'était à moi de courir derrière l'information. Je mettais un point d'honneur à me rendre dans I'entreprise de temps en temps pour dire : "Je suis toujours là. » J'ai demandé à la DRH de m'envoyer le journal interne. Je lui ai dit que j'aurais pu participer aux réunions mensuelles, si on m'avait tenue au courant. Je n'ai pas davantage été prévenue pour le repas de service ou la réunion traditionnelle de fin d'année... C'est dommage : je pense qu'il faudrait réintégrer petit à petit les personnes dans mon cas.

J'ai repris partiellement le travail. Les cures d'iode m'imposant des périodes d'absence répétées, j'ai demandé à travailler en mitemps thérapeutique dans une filiale de la maison mère qui se trouve plus près de chez moi. J'ai été bien accueillie sur le plan humain, et au début, j'étais contente de retrouver une activité professionnelle. Mais I'entreprise n'avait pas vraiment planifié mon arrivée, et j'ai eu l'impression de rétrograder, en faisant le standard ou les photocopies. Après 15 jours de ce régime, j'étais démoralisée. J'ai provoqué un entretien avec la responsable $\mathrm{RH}$ pour lui expliquer qu'il fallait que je mette toutes les chances de mon côté, notamment sur le plan moral, et que la configuration actuelle ne me satisfaisait pas. Elle a très bien compris, et lorsque je suis revenue à mon poste, après une nouvelle cure, j'avais un bureau, un ordinateur, et j'ai pu me former à de nouveaux logiciels. Je travaille, j'ai remis à jour mes connaissances. Mais j'ai le sentiment de ne plus être complètement salariée, de ne plus avoir de statut social. Je n'ai plus d'entretien d'évaluation, par exemple. Or ce n'est pas parce que je suis malade que je n'ai pas envie d'évoluer. Je fais pourtant les mêmes choses, j'occupe les mêmes fonctions que les autres... mais en réalité, je ne bénéficie pas des mêmes droits. Les entreprises ne sont pas prêtes à accueillir quelqu'un comme moi.

Ma société a annoncé la mise en place d'une politique handicap : vaste fumisterie ! Pourquoi ne questionne-t-elle pas les salariés vraiment concernés par cette problématique ? Je suis malade, ça ne se voit pas, les gens me disent que je suis dynamique et que je ne plains jamais, mais c'est un handicap, ne serait-ce qu'au niveau de la fatigue que je ressens.

Il est possible que le cancer soit un compagnon durable dans ma vie. Paradoxalement, je suis mieux dans ma peau aujourd'hui qu'avant ma maladie, même si j'ai un peu perdu confiance en l'être humain. Je vis plus intensément. Je n'ai pas le sentiment d'avoir vécu cette maladie pour rien. »

Propos recueillis par Claire Aubé claire.aube@la-maison-du-cancer.com 